\title{
Diffusion bonding of AZ91 using a silver interlayer
}

\author{
O. Torun ${ }^{\mathrm{a}, *}$, A. Karabulut ${ }^{\mathrm{b}}$, B. Baksan ${ }^{\mathrm{c}}$, İ. Çelikyürek ${ }^{\mathrm{c}}$ \\ ${ }^{a}$ AKU Bolvadin Vocational School, 03300 Bolvadin, Afyonkarahisar, Turkey \\ ${ }^{\mathrm{b}}$ AKU, Technical Education Faculty, Afyonkarahisar, Turkey \\ ' Eskişehir Osmangazi University, Institute of Metallurgy, Eskisehir, Turkey
}

\section{A R T I C L E I N F O}

Article history:

Received 9 November 2007

Accepted 2 April 2008

Available online 7 April 2008

\section{Keywords:}

A. Non-ferrous metals and alloys

D. Bonding

G. Scanning electron microscopy

\begin{abstract}
A B S T R A C T
Diffusion bonding of AZ91 alloy with a silver interlayer was carried out at $480^{\circ} \mathrm{C}$ for different times under $1 \mathrm{MPa}$ in a vacuum of $2 \times 10^{-3} \mathrm{~Pa}$. Shear test was applied to measure the shear strengths of the joints in the room temperature. The shear strength values of all bonded samples were found around 65-70 MPa. SEM-EDS studies indicated that the melting occurred along the interface of bonded samples as a result of transfer of atoms between the interlayer and the matrix during bonding. XRD results confirmed that the interlayer dissolved in the interface of joints. Investigations of the fracture surfaces showed that a good bonding was obtained by plastic deformation.
\end{abstract}

() 2008 Elsevier Ltd. All rights reserved.

\section{Introduction}

Die-cast magnesium alloys offering good combination of castability, corrosion resistance and mechanical properties are widely used for structural applications including automotive, industrial, materials-handling, commercial, and aerospace equipment $[1,2]$. The disadvantages of these materials are the poor workability, limited ductility and low stiffness because of their hexagonal structure and the degradation of mechanical properties at elevated temperatures [3-5]. As a general means of materials manufacturing, welding can be used to optimize product design and minimize the cost production. Information published on welding of magnesium alloys were still limited. Welding methods such as TIG, LBW, electron beam welding, friction welding and diffusion welding have already been applied to join magnesium alloys [6,7].

Diffusion bonding is a solid state joining technique and has widely used in titanium alloys, aluminum alloys, steels, and iron aluminides [8-10]. During diffusion bonding two clean surfaces are brought into contact under vacuum or atmosphere at low pressure and elevated temperature less than $0.7 \mathrm{Tm}[10,11]$. Many factors affect the quality of diffusion bonds, including temperature, pressure, time, metallurgical effects and interlayer. The optimal conditions to produce high quality diffusion bonds have already been reported for aluminum alloys, titanium alloys and steels [11].

Recently, the use of interlayers has been investigated for bonding of the magnesium alloys. Aluminum foil was used as interlayer on the bonding of $\mathrm{TiC}$ reinforced magnesium metal matrix composites $\left(\mathrm{TiC}_{\mathrm{p}} / \mathrm{AZ91D}\right)$ and magnesium alloy (Mg-3Al-1Zn). These stud-

\footnotetext{
* Corresponding author. Tel.: +90 272 6126353; fax: +90 2726116353 .

E-mail address: otorun@aku.edu.tr (O. Torun).
}

ies demonstrate the possibility of fabricating magnesium alloy products using suitable interlayer [12,13]. In the present paper, the possibility of joining AZ91 alloy using a silver foil interlayer was investigated. The microstructure and mechanical properties of bonded samples were examined.

\section{Experimental}

The alloy AZ91 (Mg-9Al-1Zn) was melted in a graphite crucible in vacuum furnace under argon atmosphere at $750{ }^{\circ} \mathrm{C}$. Then the molten metal was cast into metal molds with $10 \mathrm{~mm}$ diameter under protective gas. The samples were machined to $8 \mathrm{~mm}$ diameter and $10 \mathrm{~mm}$ height. They were ground, polished with $1 \mu \mathrm{m}$ diamond paste and then cleaned in acetone. The silver foil used as interlayer was also cleaned in acetone. Thickness of the interlayer was measured around $100 \mu \mathrm{m}$. Bonding process was carried out at $480{ }^{\circ} \mathrm{C}$ for durations of $0.5,1$ and $2 \mathrm{~h}$ under $1 \mathrm{MPa}$ pressure in a vacuum of $2 \times 10^{-3} \mathrm{~Pa}$ using diffusion welding furnace [14]. The heat rate of the furnace was kept $1{ }^{\circ} \mathrm{C} / \mathrm{s}$. After the diffusion bonding, the samples cooled to room temperature in air and no heat treatment was applied.

Bonded samples were cut perpendicular to the bonding interface. The specimens were prepared according to standard metallographic procedures. Microstructures of original AZ91 alloy, bond region and fracture surfaces were characterized by optical microscopy and scanning electron microscopy. The chemical compositions of the bond interface and the matrix were determined using energy dispersive X-ray spectrometry (EDS). Microhardness measurements were made on both sides of the bonded samples by means of Vickers indenter with a load of $50 \mathrm{~g}$ with $20 \mathrm{~s}$ indenting time. Phase identification was performed using $\mathrm{X}$-ray analysis on the fractured specimen surfaces using Copper X-ray radiation with a nickel filter.

A specially testing apparatus was designed to determine bond shear strength because of not enough large of the bonded samples (Fig. 1). Bonded samples were inserted in the testing apparatus and the testing apparatus was placed on a tensile machine. Tests were carried out at room temperature and loading speed of $0.3 \mathrm{~mm} /$ min. Three samples were tested for each bonding condition and their averages were taken. In addition, to compare with the shear strength of bonded samples, cast AZ91 was annealed at $480^{\circ} \mathrm{C}$ for $2 \mathrm{~h}$, and then the shear test was applied. The mode of fracture of the shear test pieces bonded for different times was characterized by SEM examination. 


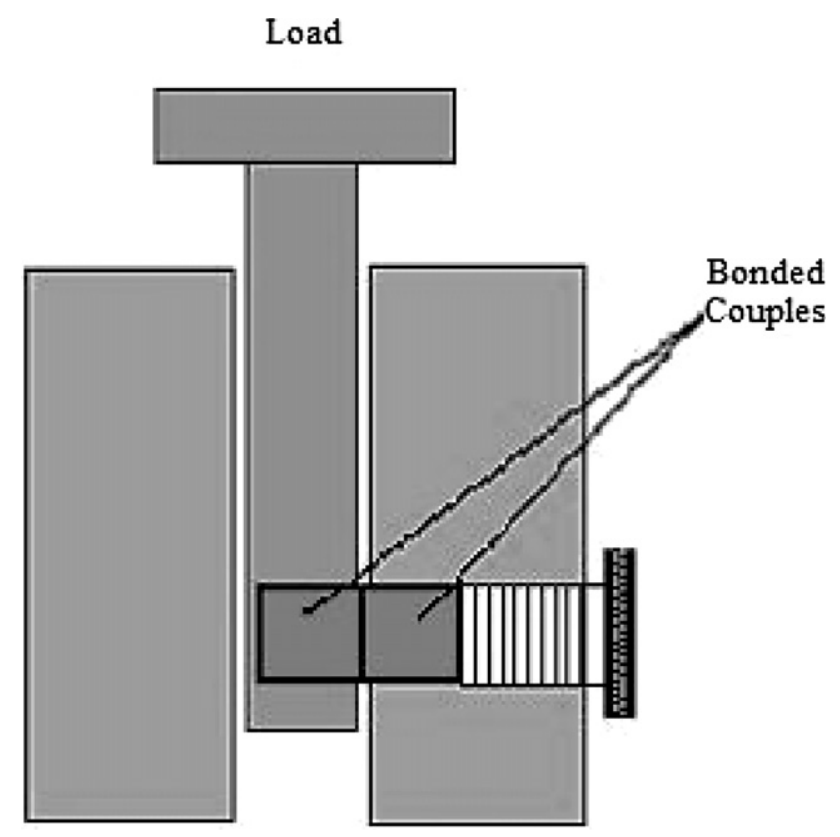

Fig. 1. Schematic illustration of shear strength testing apparatus.

\section{Results and discussion}

Optical microstructure of as-cast AZ91 is shown in Fig. 2. This image demonstrates the $\alpha$-matrix and $\alpha-\beta$ phase mixture formed along grain boundaries [15]. Scanning electron microscopy examinations in the secondary electron mode using metallographically prepared samples demonstrated that most of the interlayer dissolved in the bond interface of bonded samples for various times, as seen in Fig. 3. SEM-EDS analysis taken from the center of the bond interface into the matrix shows that the chemical compositions of the bonded samples for $0.5,1$ and $2 \mathrm{~h}$ are similar (Fig. 4). According to $\mathrm{Mg}-\mathrm{Ag}$ phase diagram, partial melting occurs at the bond region during diffusion bonding when the concentration of solute atoms reach to a certain level. As a result of this situation, the melting occurred along the bond interface of samples and $\mathrm{Ag}$ interlayer dissolved in the matrix. Scanning electron microscopy

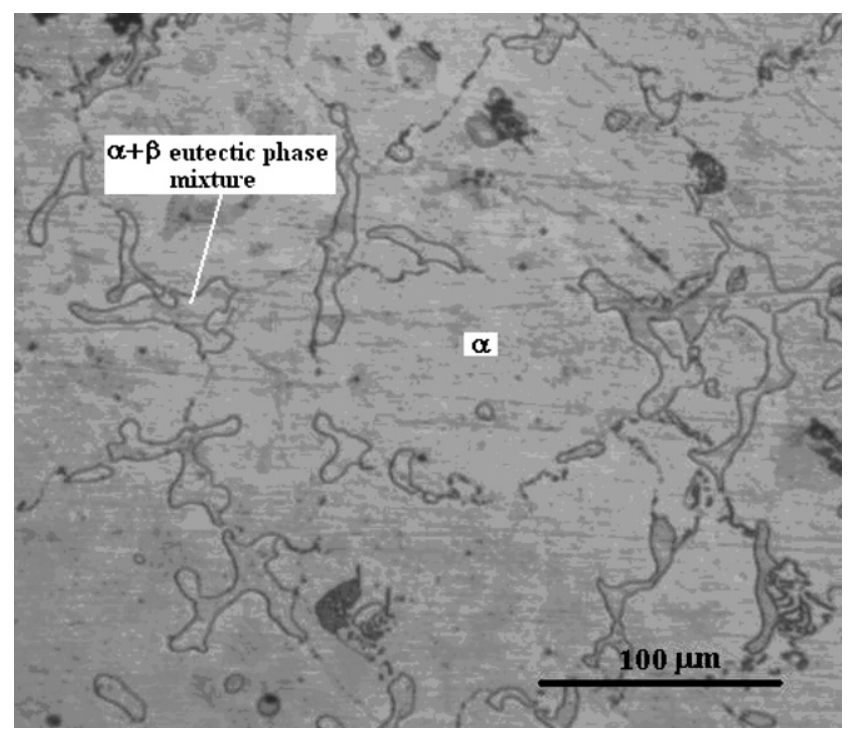

Fig. 2. Optical micrograph of the cast AZ91.
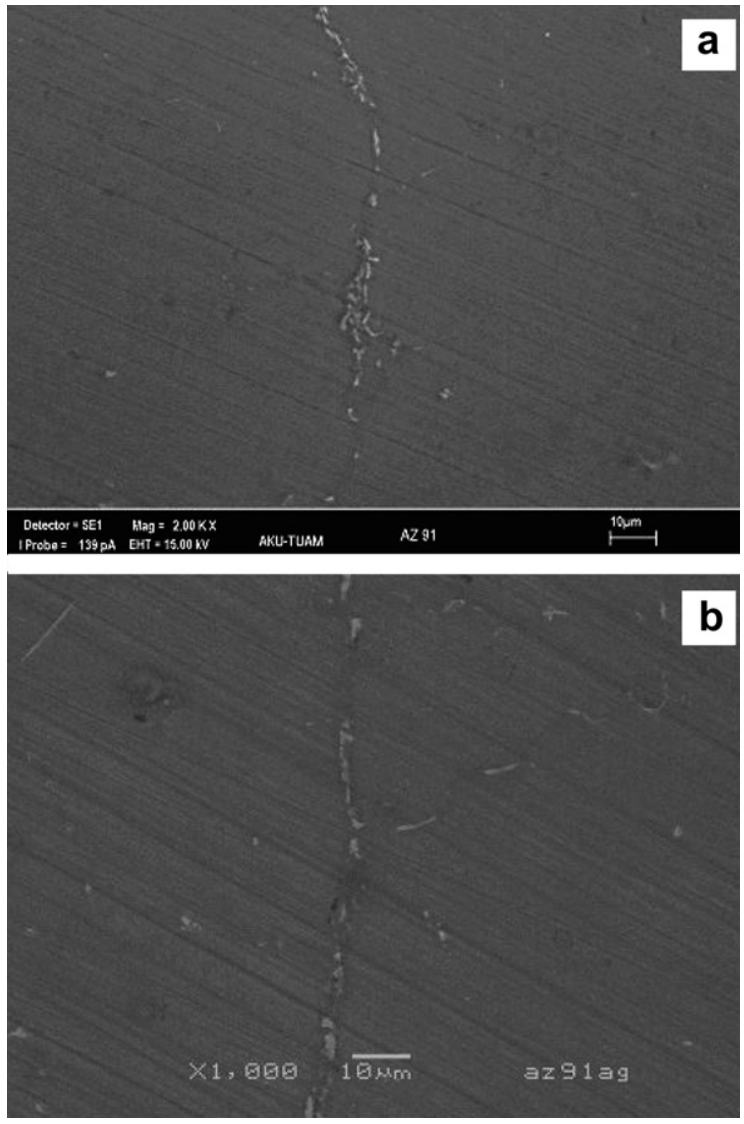

Fig. 3. SEM images of the bonded samples for (a) $0.5 \mathrm{~h}$ and (b) $2 \mathrm{~h}$.
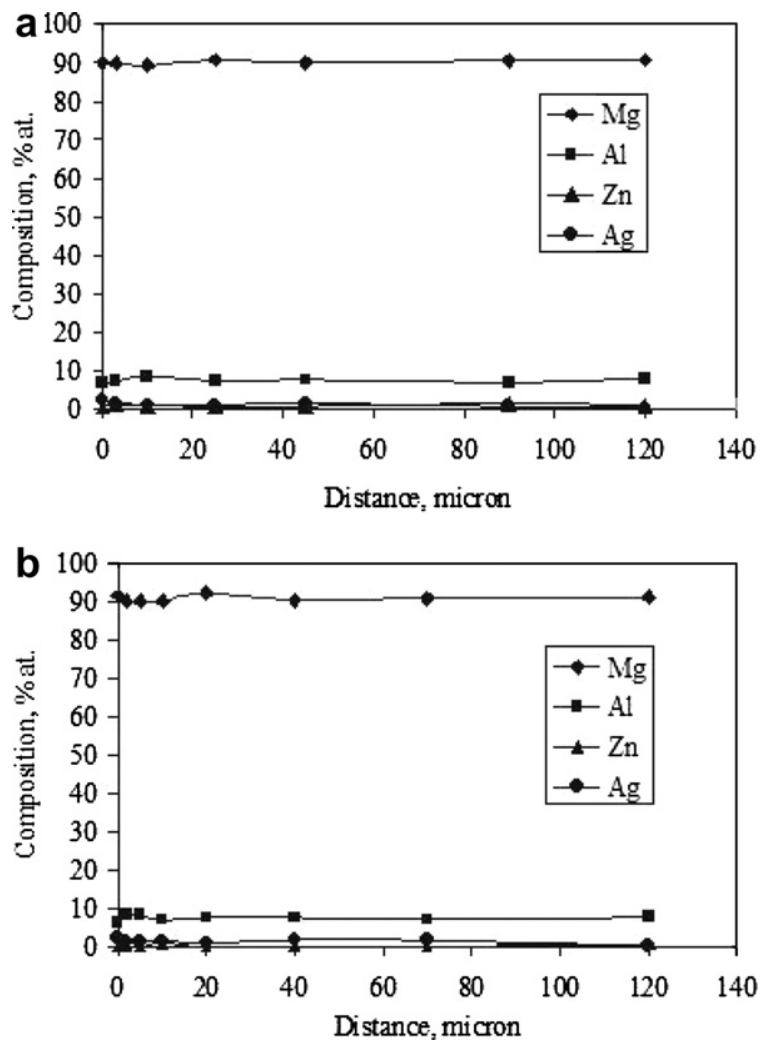

Fig. 4. Distribution of $\mathrm{Mg}, \mathrm{Al}, \mathrm{Zn}$ and $\mathrm{Ag}$ atoms in the interface of the bonded samples for (a) $0.5 \mathrm{~h}$ and (b) $2 \mathrm{~h}$. 


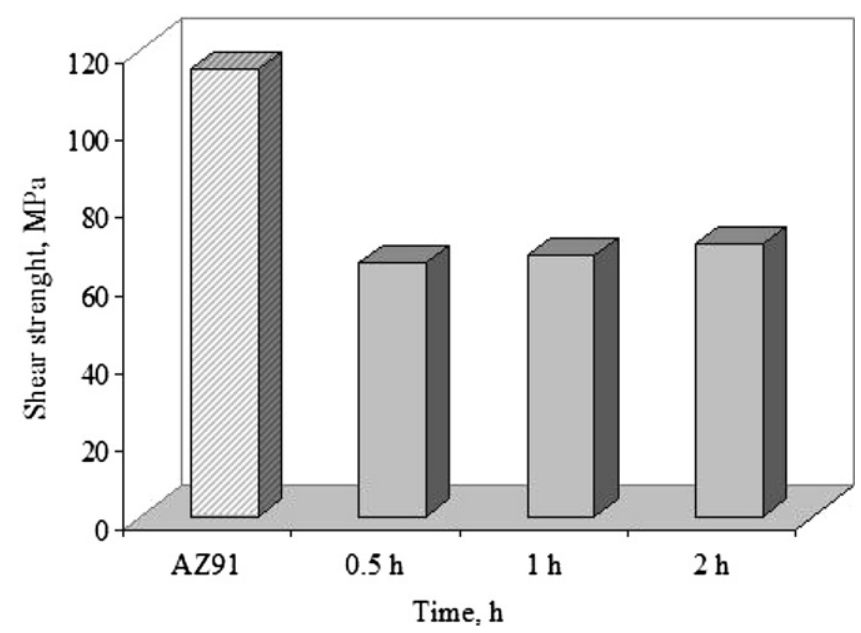

Fig. 5. Variation of shear strengths of the bounded samples with increasing of the bonding time.

examinations and EDS analysis results show that all bonded samples exhibit same behaviors.

For all bonding times, microhardness measurements taken from the bond interface and the matrix revealed that there is no significant hardness variation. The hardness values are almost the same as for the base metal AZ91. The shear strengths of AZ91 annealed for $2 \mathrm{~h}$ at $480^{\circ} \mathrm{C}$ and the bonded samples for various times were determined using testing apparatus. The shear strengths of the base alloy and the bonded samples variation of the bonding time are shown in Fig. 5. Under the experimental conditions, the results show that increasing the diffusion bonding time does not cause important variation in the shear strengths of bonded samples.
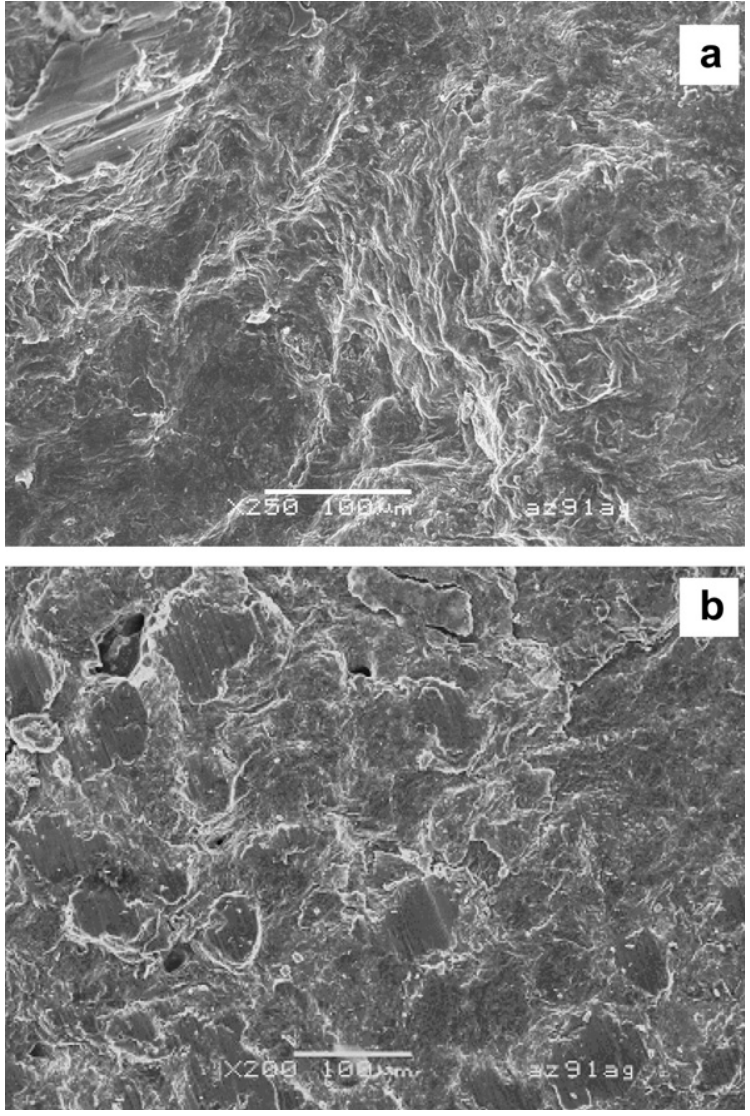

Fig. 6. Micrographs of fracture surfaces of the bonded samples for $(\mathrm{a}) 1 \mathrm{~h}$ and (b) $2 \mathrm{~h}$.
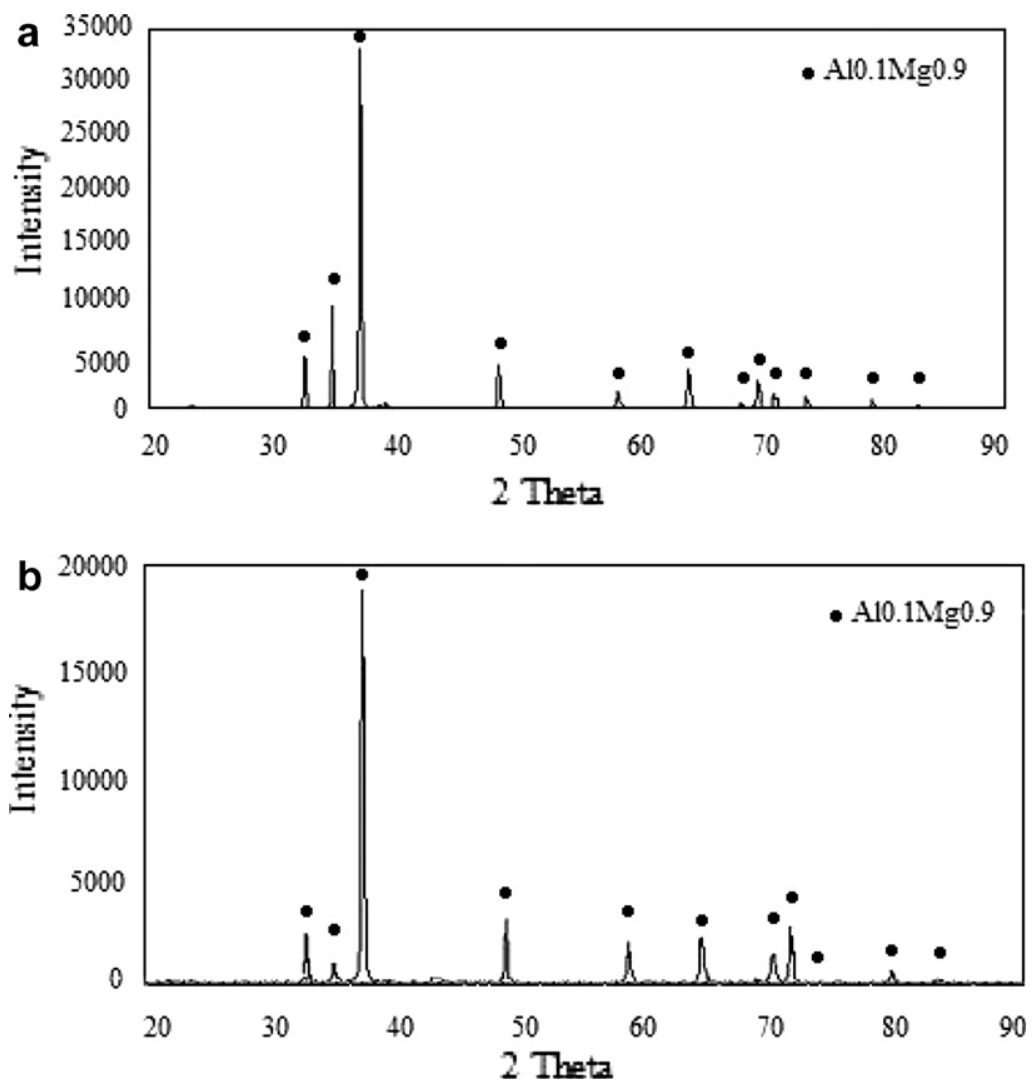

Fig. 7. X-ray diffraction patterns of fractured surfaces of diffusion bonded samples for (a) $1 \mathrm{~h}$ and (b) 2 h. 
The shear strengths of the bonded samples are almost independent of the bonding time. The shear strengths of bonded samples for different times are very close because the microstructure and the chemical composition of the bond interface of bonded samples for different times are similar.

SEM observations of the fractured surfaces of the bonded samples show the presence of plastic deformation as seen in Fig. 6. No oxides and/or other contaminants are observed on the fracture surfaces. The XRD patterns of the fractured surfaces indicate that Al0.1Mg0.9 phase forms (Fig. 7).

\section{Conclusion}

Vacuum diffusion bonding of AZ91 alloy with silver interlayer was carried out successively at $480{ }^{\circ} \mathrm{C}$ for different durations under $1 \mathrm{MPa}$ in a vacuum of $2 \times 10^{-3} \mathrm{~Pa}$. During the bonding process, the melting occurred along the bond interface of samples and Ag interlayer dissolved in the matrix. After the bonding process, the macro deformation was not observed at the bonded samples. All bonded samples were produced with sound bonding without any micropore, microcrack and oxide. The shear strengths are very close because the microstructures and the chemical compositions of the bonded samples are similar. Under the experimental conditions, the shear strengths of the bonded samples are almost independent of the bonding time.

\section{Acknowledgements}

The author is grateful to Afyonkarahisar Kocatepe University Scientific Research Committee since this study is supported (Project No. 051.TEF.02).

\section{References}

[1] Properties and selection: nonferrous alloys and special purpose materials. Metals Handbook, 10th ed.; 1990. p. 2.

[2] Lü YZ, Wang QD, Ding WJ, Zeng XQ, Zhu YP. Fracture behavior of AZ91 magnesium alloy. Mater Lett 2000;445:265-8.

[3] Mathis K, Gubicza J, Nam NH. Microstructure and mechanical behavior of AZ91 $\mathrm{Mg}$ alloy processed by equal channel angular pressing. J Alloys Compd 2005;394:194-9.

[4] Cavaliere P, De Marco PP. Superplastic behaviour of friction stir processed AZ91 magnesium alloy produced by high pressure die cast. J Mater Process Technol 2007;184:77-83.

[5] Cao X, Jahazi M, Immarigeon JP, Wallace W. A review of laser welding techniques for magnesium alloys. J Mater Process Tech 2006;171:188-204.

[6] Liming L, Jifeng W, Gang S. Hybrid laser-TIG welding, laser beam welding and gas tungsten arc welding of AZ31B magnesium alloy. Mater Sci Eng A 2004;381:129-33.

[7] Somekawa H, Watanble H, Mukai T, Higashi K. Low temperature diffusion bonding in a superplastic AZ31 magnesium alloy. Scripta Mater 2003:48:1249-54.

[8] Duarte LI, Ramos AS, Vieira MF, Viana F, Vieira MT, Koçak M. Solid-state diffusion bonding of gamma-TiAl alloys using Ti/Al thin films as interlayers. Intermetallics 2006;14:1151-6.

[9] Juan W, Yajiang L, Haijun M. Study of diffusion bonding of Fe-28Al alloy with austenitic stainless steel in vacuum. Vacuum 2006;80:426-31.

[10] Torun O, Gürler R, Baksan B, Çelikyürek İ. Diffusion bonding of iron aluminide Fe72Al28 using a pure iron interlayer. Intermetallics 2005;13:801-4.

[11] Somekawa $H$, Watanble $H$, Mukai T, Higashi $K$. Diffusion bonding in superplastic magnesium alloys. Mater Sci Eng 2003;A339:328-33.

[12] Sun DQ, Gu XY, Liu WH. Transient liquid phase bonding of magnesium alloy (Mg-3Al-1Zn) using aluminium interlayer. Mater Sci Eng A 2005;391:29-33.

[13] Gu XY, Sun DQ, Liu L. Transient liquid phase bonding of TiC reinforced magnesium metal matrix composites (TiCP/AZ91D) using aluminum interlayer. Mater Sci Eng A 2007. doi:10.1016/j.msea.2007.09.064.

[14] Aydın M, Gürler R, Baksan B. A diffusion welding instrument for welding metals and metal based materials without melting. Turkish Patent Institute. Patent No: TR-2002-02710-Y.

[15] Anık M, Avcı P, Tanverdi A, Çelikyürek I, Baksan B, Gürler R. Effect of the eutectic phase mixture on the anodic behavior of alloy AZ91. Mater Des 2006;27:347-55. 